\title{
Growth patterns of breast fed and formula fed infants in the first 12 months of life: an Italian study
}

\author{
C Agostoni, F Grandi, M L Gianni, M Silano, M Torcoletti, M Giovannini, E Riva
}

\begin{abstract}
Aim-To compare the growth patterns of breast fed and formula fed Italian infants in the first 12 months of life using World Health Organisation (WHO) reference data.

Methods-The growth patterns of 73 breast fed infants ( 36 male, 37 female) and 65 formula fed infants ( 35 male, 30 female) were compared. Solid foods were introduced with the same weaning schedules from the 5th month in both groups. The weight for age (WA), length for age (LA), and weight for length (WL) $z$ scores (National Center for Health StatisticsWHO data) were calculated at birth, 1, 2, 3, 4, 6, 9, and 12 months.

Results-Breast fed infants had the highest $\mathrm{z}$ scores (WA, WL) at birth. Breast fed groups had significantly higher growth indices at 1 month (WA, LA), 2 months (WA) and 3 months (WA, LA) of age. Compared to breast fed groups, formula fed infants showed significantly higher WA $z$ score changes in the $1-2,2-3,3-4$, and 4-6 month intervals. LA $z$ score changes were higher for breast fed infants at 0-1 month and for the formula fed infants at 4-6 months. In the 6-12 month interval growth indices progressively increased for the formula fed infants and declined for infants breast fed for longer (12 months). The 0-12 month changes in WA, LA, and WL $\mathrm{z}$ scores were positive for formula fed infants and negative for the 12 month breast fed group. Nevertheless, the 12 month breast fed group showed an absolute WA $\mathrm{z}$ score just below 0 (mean (SEM) $-0.04(0.26))$ at 12 months.
\end{abstract}

Conclusion-The growth pattern of breast fed and formula fed Italian infants differs in the first 12 months of life. This questions the validity of current reference values for monitoring the growth of breast fed infants. Growth indices in breast fed groups, high at birth and closer than expected to the reference at 12 months, may reflect differences in genetic factors, intrauterine conditions, or both.

(Arch Dis Child 1999;81:395-399)

Keywords: breast feeding; formula feeding; infant feeding practice; growth

Recent studies from North American and north European countries comparing infants' growth with the National Center for Health
Statistics-World Health Organisation (NCHSWHO) reference data in the first year of life ("12 month breast fed pooled dataset") have identified different patterns in breast fed and formula fed infants, the breast fed infants showing a reduced rate of accretion, particularly in weight for age (WA), from the third up to the 12th month of life. ${ }^{12}$ The WHO promotes breast feeding as ideal for the nutrition of infants; infants living in favourable conditions and fed according to WHO recommendations show significant deviation from current NCHS-WHO reference growth patterns, which are mainly based on formula fed subjects. ${ }^{3}$ Consequently an ad hoc working group has recently identified the need for a new reference derived from populations fed according to current recommendations. ${ }^{45}$

The currently used " 12 month breast fed pooled dataset" mainly consists of North American and north European white infants. It has been recommended that investigations should be performed on ethnically diverse populations, ${ }^{1}$ providing these live in a "healthy" environment which does not limit growth. Moreover, since weaning schedules and nutrient composition of complementary foods may influence growth patterns, and the weaning process follows traditional habits rather than scientific issues, ${ }^{6}$ data are needed from different countries to determine the consistency of different growth patterns with different weaning habits.

To address these issues we compared the growth patterns of two groups of breast fed and formula fed Italian infants.

\section{Methods}

SUBJECTS

Eligibility was defined by gestational age between the completed 37th and 42nd week, weight at birth ranging from 2500-5000 g, Apgar score higher than 7 at five minutes, and absence of disease. The definition of gestational age was based on the last menstruation date and confirmed by an ultrasound examination performed by the 20th week. Mothers had no chronic illness and were recruited within 24 hours after delivery.

The criteria for inclusion in the breast fed group were: (a) data available on growth during the first 12 months of life for infants fully breast fed for at least 4 months; (b) measurement intervals no greater than 2 months in the first 6 months of life and no greater than 3 months in the second 6 months of life; (c) information available on the duration of breast feeding, use 
Table 1 Characteristics of mothers (mean (SD) when not otherwise indicated) in breast fed and formula fed infants

\begin{tabular}{llll}
\hline Characteristic & $\begin{array}{l}\text { Breast fed } \\
(n=73)\end{array}$ & $\begin{array}{l}\text { Formula fed } \\
(n=65)\end{array}$ & $p \dagger$ \\
\hline Age (years) & $29.9(4.4)$ & $32.5(5.4)$ & $0.003^{\star}$ \\
Education (\% high) & 20.5 & 12.3 & 0.25 \\
Parity (\% primiparous) & 56.2 & 63.1 & 0.48 \\
Delivery (\% vaginal) & 83.5 & 84.6 & 0.86 \\
Pregnancy duration (weeks) & $39.2(1.2)$ & $39.2(1.4)$ & 0.95 \\
Height (cm) & $162(6)$ & $164(6)$ & 0.06 \\
Prepregnancy body weight $(\mathrm{kg})$ & $55(7)$ & $57(7)$ & 0.12 \\
Prepregnancy BMI $\left(\mathrm{kg} / \mathrm{m}^{2}\right)$ & $21.0(2.4)$ & $21.1(2.1)$ & 0.60 \\
Body weight increase $(\mathrm{kg})$ & $12.8(3.1)$ & $12.8(3.3)$ & 0.99 \\
\hline
\end{tabular}

†Student's $t$ test or $\chi^{2}$ test; * significant.

of supplemental milk, formulas, and solid foods, and the timing of their introduction; and (d) documentation of socioeconomic conditions consistent with the likely achievement of growth potential. ${ }^{12}$ Additionally, those breast fed for at least 12 months were separated and further analysed in order to make comparisons with the data obtained from the " 12 month breast fed pooled dataset".

Infants fully breast fed were given only minimal fluids other than human milk, and no solids or formula in the first 4 months, according to the definitions of the retrospective review by the WHO working group on infant growth. ${ }^{1}$ Mothers of breast fed infants were instructed not to supplement babies with sweetened liquids, in order to prevent the supply of energy sources other than human milk. In some cases breast fed infants received clear fluids with no added sugar. These infants were not "exclusively breast fed", since this definition requires that no supplemental fluids are given, but categorised as "predominantly breast fed". ${ }^{7}$ None of the 14 infants in the " 12 month breast fed pooled dataset" was given any other milk or formula in the first year of life.
Formula fed subjects were initially fed standard infant formulas, whose energy, protein, fat, carbohydrate, and micronutrient composition complied with that of the European Society of Pediatric Gastroenterology and Nutrition (ESPGAN). ${ }^{8}$ Follow up formulas were introduced during the fifth month, according to the ESPGAN indications. ${ }^{9}$ Follow up formulas were also given to breast fed infants when mothers were unable to meet the infant dietary needs with their milk during the weaning period.

Solid foods were introduced from the fifth month onwards in both groups, following a specific weaning schedule. This reflected the weaning habits in our area and provided progressive introduction of gluten free cereals, vegetables, poultry, soft cheese, and red meat at 5-6 months, cereals with gluten at 6 months, ham, fish and pulses at 7-8 months, and citrus fruits and eggs at 9-12 months. Dietary advice was given at the periodic visits and the compliance was assessed by interviewing mothers.

Mothers' height, prepregnancy body weight, and weight increase in pregnancy were obtained from the obstetric clinical records. We then derived prepregnancy body mass index (BMI) $\left(\mathrm{kg} / \mathrm{m}^{2}\right)$. The parents' socioeconomic status and education were coded according to the Italian census. Their informed consent was obtained at recruitment and the study was approved by the local ethics committee.

COLLECTION OF DATA

Clinical examinations were performed at birth, $1,2,3,4,6,9$, and 12 months of age. The permissible intervals around the actual chronological age for nominal age visits were within \pm 1 week for the first 4 months and within \pm 2 weeks for all subsequent visits. Serial weight

Table 2 Weight (g) of breast fed and formula fed infants in the first year of life

\begin{tabular}{|c|c|c|c|c|c|c|c|c|c|c|}
\hline \multirow{3}{*}{$\begin{array}{l}\text { Age } \\
\text { (months) }\end{array}$} & \multicolumn{5}{|l|}{ Male } & \multicolumn{5}{|l|}{ Female } \\
\hline & \multicolumn{2}{|l|}{ Breast fed } & \multicolumn{2}{|c|}{ Formula fed } & \multirow[b]{2}{*}{$p t$} & \multicolumn{2}{|l|}{ Breast fed } & \multicolumn{2}{|c|}{ Formula fed } & \multirow[b]{2}{*}{$p t$} \\
\hline & $n(B F) \neq$ & Mean (SD) & $n$ & Mean (SD) & & $n(B F) \neq$ & Mean (SD) & $n$ & Mean (SD) & \\
\hline 0 & $37(37)$ & $3477(405)$ & 35 & $3221(492)$ & $0.01^{\star}$ & $36(36)$ & $3342(423)$ & 30 & $3252(386)$ & 0.37 \\
\hline 1 & 37 (37) & $4219(545)$ & 35 & $3953(507)$ & $0.03^{\star}$ & $36(36)$ & $4061(538)$ & 30 & $3841(430)$ & 0.07 \\
\hline 2 & 37 (37) & $5335(424)$ & 35 & $4932(562)$ & $0.001^{\star}$ & $36(36)$ & $5091(563)$ & 30 & 4796 (385) & $0.01^{\star}$ \\
\hline 3 & 37 (37) & $6126(549)$ & 35 & $5812(601)$ & $0.01^{\star}$ & $36(36)$ & $5850(712)$ & 30 & $5587(504)$ & 0.09 \\
\hline 4 & 37 (37) & $6816(561)$ & 35 & $6608(692)$ & 0.16 & $36(36)$ & $6461(772)$ & 30 & $6251(562)$ & 0.21 \\
\hline 6 & $36(32)$ & $7915(636)$ & 31 & $7990(736)$ & 0.67 & 35 (35) & $7417(996)$ & 28 & $7525(758)$ & 0.64 \\
\hline 9 & $30(18)$ & $9367(1001)$ & 31 & $9476(983)$ & 0.67 & $27(13)$ & $8752(1134)$ & 26 & $8893(981)$ & 0.64 \\
\hline 12 & $33(8)$ & $10306(1113)$ & 31 & $10368(1043)$ & 0.82 & $28(6)$ & $9723(1142)$ & 25 & $9839(1072)$ & 0.70 \\
\hline
\end{tabular}

†Student's $t$ test; ${ }^{\star}$ significant.

¥Infants actually being breast fed (BF) at each assessment.

Table 3 Length $(\mathrm{cm})$ of breast fed and formula fed infants in the first year of life

\begin{tabular}{|c|c|c|c|c|c|c|c|c|c|c|}
\hline \multirow[b]{3}{*}{ Age (months) } & \multicolumn{5}{|l|}{ Male } & \multicolumn{5}{|l|}{ Female } \\
\hline & \multicolumn{2}{|l|}{ Breast fed } & \multicolumn{2}{|c|}{ Formula fed } & \multirow[b]{2}{*}{$p t$} & \multicolumn{2}{|l|}{ Breast fed } & \multicolumn{2}{|c|}{ Formula fed } & \multirow[b]{2}{*}{ pt } \\
\hline & $n(B F) \neq$ & Mean (SD) & $n$ & Mean (SD) & & $n(B F) \neq$ & Mean (SD) & $n$ & Mean (SD) & \\
\hline 0 & $37(37)$ & $50.8(1.80)$ & 35 & $50.5(2.12)$ & 0.50 & $36(36)$ & $49.8(1.19)$ & 30 & $49.6(2.03)$ & 0.70 \\
\hline 1 & $37(37)$ & $54.7(2.40)$ & 35 & $53.7(2.04)$ & $0.05^{\star}$ & $36(36)$ & $53.3(2.13)$ & 30 & $53.2(2.13)$ & 0.92 \\
\hline 2 & 37 (37) & $58.4(1.95)$ & 35 & $57.2(2.00)$ & $0.01^{\star}$ & $36(36)$ & $56.9(2.07)$ & 30 & $56.8(2.20)$ & 0.76 \\
\hline 3 & $37(37)$ & $61.4(2.03)$ & 35 & $59.8(2.51)$ & $0.005^{\star}$ & $36(36)$ & $59.7(2.39)$ & 30 & $59.6(2.34)$ & 0.83 \\
\hline 4 & 37 (37) & $63.9(1.79)$ & 35 & $62.9(2.20)$ & $0.03^{\star}$ & $36(36)$ & $62.4(2.37)$ & 30 & $62.0(2.45)$ & 0.52 \\
\hline 6 & $36(32)$ & $68.0(2.24)$ & 31 & $67.5(2.43)$ & 0.38 & $35(35)$ & $65.7(2.57)$ & 28 & $66.5(2.33)$ & 0.21 \\
\hline 9 & $30(18)$ & $73.3(2.51)$ & 31 & $72.5(2.55)$ & 0.22 & 27 (13) & $70.4(2.47)$ & 26 & $71.2(2.90)$ & 0.28 \\
\hline 12 & $33(8)$ & $77.1(3.28)$ & 31 & $76.3(2.80)$ & 0.30 & $28(6)$ & $74.2(2.42)$ & 25 & $74.9(2.86)$ & 0.34 \\
\hline
\end{tabular}

+Student's $t$ test; * significant

$\ddagger$ Infants actually being breast fed (BF) at each assessment. 


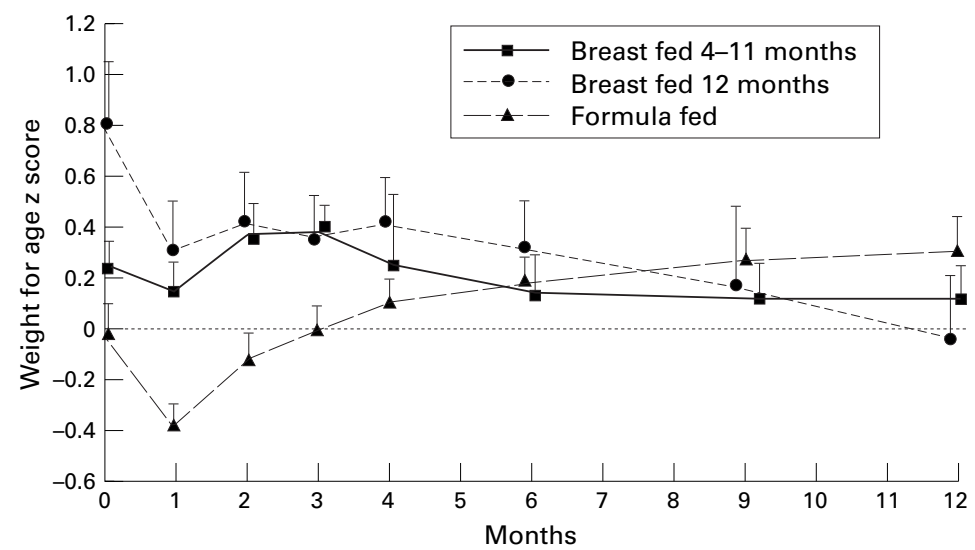

Figure 1 Mean (SEM) WA z scores in breast fed (4-11 months, and 12 months) and formula fed infants.

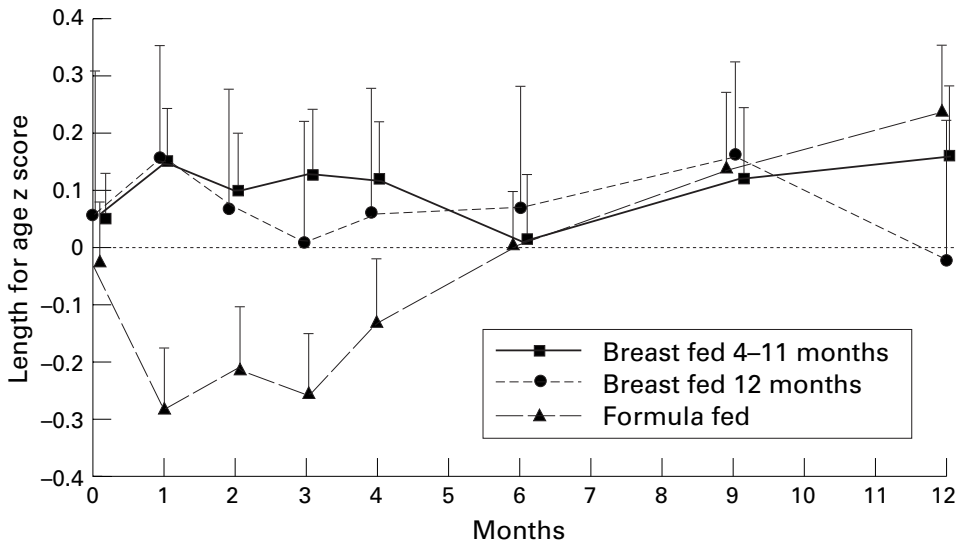

Figure 2 Mean (SEM) LA z scores in breast fed (4-11 months, and 12 months) and formula fed infants.

and recumbent length were measured by standardised techniques. Babies were weighed naked on an electronic Sartorius scale accurate to $\pm 5 \mathrm{~g}$. Crown-heel length was measured on a portable measuring board. All measurements were performed by the same two trained personnel. Actual chronological decimal age was used to calculate the standardized $\mathrm{z}$ score anthropometric indexes. The $\mathrm{z}$ scores represent the distance in SD units from the normative reference means for age and sex of the NCHS-WHO. ${ }^{10}$ The WA, length for age (LA),

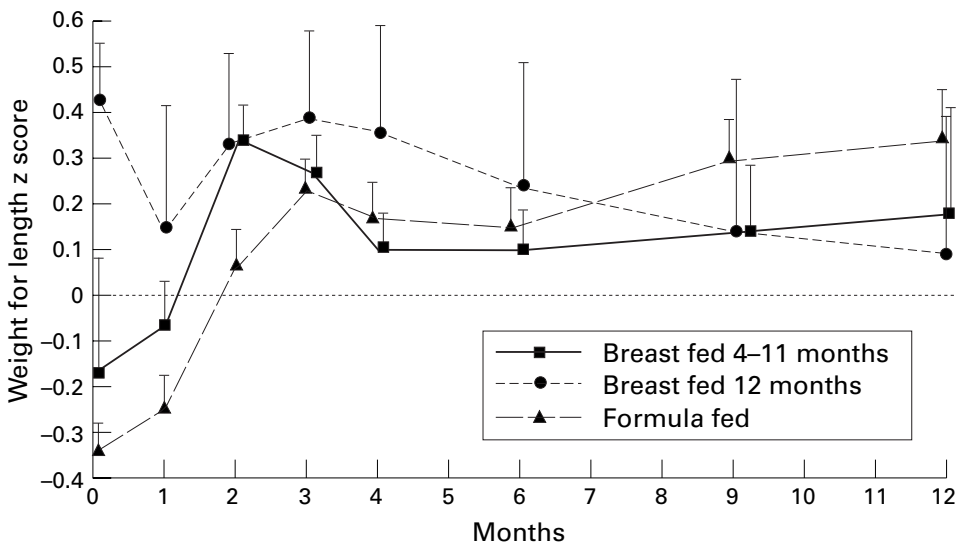

Figure 3 Mean (SEM) WL z scores in breast fed (4-11 months, and 12 months) and formula fed infants. Values at birth have been calculated for 49 formula fed infants, 55 infants breast fed for 4-11 months, and 12 infants breast fed for 12 months, as standardised data are unavailable for lengths $<49 \mathrm{~cm}$. and weight for length (WL) values were calculated by means of the ANTHRO pediatric anthropometry software program (version 1.01, 1990, Centers for Disease Control and Prevention, Atlanta, Georgia, USA).

STATISTICAL ANALYSES

The study was designed to detect a between group z score difference of $50 \%$ at any time on the basis of a significance level $\alpha=0.05$, with a power of the test equal to $80 \%$. This required at least 64 infants in each of the two groups. Data for these two groups are reported as mean (SD). Student's $t$ test and $\chi^{2}$ test were used for comparisons between continuous and discrete variables. We compared the groups, including separate analysis of the 12 month breast fed group data, as mean (SEM) with the values of significance derived from non-parametric tests (with two groups, Mann-Whitney test; with three groups, Kruskal-Wallis test and Dunn's post hoc analysis). Multivariate analysis was used to adjust values at birth for demographic characteristics. All analyses were made with the SPSS 8.0 statistical computer package (SPSS Inc, Chicago, Illinois, USA).

\section{Results}

Seventy three breast fed (36 male, 37 female) and 65 formula fed (35 male, 30 female) infants were followed from birth. Breast fed infants represented those fully breast fed for 4 months from an initial sample of 92 subjects whose mothers gave informed consent. Among the 92 breast fed infants initially recruited, 19 were excluded because complementary formula feeds had been given before the completion of the fourth month of life. Fourteen infants (eight male and six female) were breast fed for the entire first 12 months of life. The formula fed group included all healthy infants born at term in our maternity ward within a nine month period (total deliveries 1168) whose mothers chose to feed artificially and agreed to be recruited into the study. Reasons for exclusion were family relocation, intercurrent infections, and parents' withdrawal.

The median duration of breast feeding for the 4-11 month breast fed group was 6 months. The maternal characteristics for the breast fed and formula fed groups are presented in table 1 . The 12 month breast feeding mothers showed no difference in demographic and anthropometric characteristics and body weight gain during pregnancy (data not shown) from those breast feeding less than 12 months.

Breast fed infants were heavier at birth than formula fed infants (3410 (417) v 3235 (443) $\mathrm{g}, \mathrm{p}<0.02)$ with no length differences $(50.3$ (1.6) v $50.1(2.1) \mathrm{cm}, \mathrm{p}=0.46)$. The weight and length absolute values, according to sex, are presented in tables 2 and 3 . The differences in weight and length between breast fed and formula fed groups were more notable in boys than girls throughout the year.

In analysing growth progression over the year by means of $\mathrm{z}$ score values, we evaluated the 12 month breast fed group separately.

Figures 1, 2, and 3 show the mean (SEM) WA, LA, and WL $\mathrm{z}$ scores, respectively, for the 
two breast fed groups (4-11 months, and 12 months) and the formula fed group. The values are calculated for all infants presenting at each control. The WA $\mathrm{z}$ score at birth was higher for the 12 month breast fed infants than for the formula fed counterparts $(\Delta=0.82$, SEM $=0.30, p=0.005)$. The difference persisted even after adjustment for parity, parental education, and social class (adjusted $\Delta=0.99$, SEM $=0.16, p=0.003)$. Compared to formula fed infants, both breast fed groups showed significantly higher WA values at 1 month $(p<0.001)$ and 2 months $(p=0.002)$, and higher LA values in the 1-3 month period, reaching significance in the 4-11 month breast fed group $(p=0.01$ at 1 month and $p=0.04$ at 3 months). The WL value of the 12 month breast fed group was significantly higher at birth $(p=0.002)$, while no WL differences were present among the three groups at 12 months.

The changes at the periodic intervals $(\Delta$ values) have been calculated for subjects presenting at two consecutive examinations and those whose data were available at birth and 12 months (table 4). Formula fed infants show a lower WA $\mathrm{z}$ score change in the $0-1$ month period and significantly higher WA $\mathrm{z}$ score changes in the $1-2,2-3,3-4$, and 4-6 month intervals. The WA increment for the formula fed group mainly comprised the "catch up" of the differences present at birth with the breast fed groups. LA z score changes were higher for breast fed groups in the $0-1$ month interval and for formula fed infants in the 4-6 month period. Formula fed infants

Table 4 Mean (SEM) $\triangle$ changes of WA, LA, and WL $z$ scores in the study groups at the periodic examinations

\begin{tabular}{|c|c|c|c|c|}
\hline & $\begin{array}{l}12 \text { months } \\
\text { breast fed }\end{array}$ & $\begin{array}{l}4-11 \text { months } \\
\text { breast fed }\end{array}$ & Formula fed & $p t$ \\
\hline$\Delta 0-1$ month & $\mathrm{n}=14$ & $\mathrm{n}=59$ & $\mathrm{n}=65$ & \\
\hline WA & $-0.49(0.13)$ & $-0.13(0.07)^{\mathrm{a}}$ & $-0.36(0.06)^{\mathrm{b}}$ & $0.01^{\star}$ \\
\hline $\mathrm{LA}$ & $\begin{array}{l}0.09(0.23) \\
\mathrm{n}=12\end{array}$ & $\begin{array}{l}0.09(0.08)^{\mathrm{a}} \\
\mathrm{n}=55\end{array}$ & $\begin{array}{l}-0.24(0.08)^{b} \\
\mathrm{n}=49\end{array}$ & $0.01^{\star}$ \\
\hline WL & $-0.20(0.19)$ & $0.11(0.10)$ & $0.14(0.09)$ & 0.49 \\
\hline$\Delta 1-2$ months & $\mathrm{n}=14$ & $\mathrm{n}=59$ & $\mathrm{n}=65$ & \\
\hline WA & $0.11(0.19)^{a}$ & $0.23(0.07)$ & $0.27(0.04)^{\mathrm{b}}$ & $0.03^{\star}$ \\
\hline LA & $-0.08(0.16)$ & $-0.05(0.08)$ & $0.07(0.05)$ & 0.24 \\
\hline WL & $0.18(0.15)$ & $0.40(0.08)$ & $0.32(0.06)$ & 0.63 \\
\hline$\Delta 2-3$ months & $\mathrm{n}=14$ & $\mathrm{n}=59$ & $\mathrm{n}=64$ & \\
\hline WA & $-0.04(0.06)$ & $0.01(0.04)^{\mathrm{a}}$ & $0.12(0.03)^{\mathrm{b}}$ & $0.005^{\star}$ \\
\hline LA & $-0.06(0.10)$ & $0.03(0.06)$ & $-0.04(0.06)$ & 0.76 \\
\hline WL & $0.06(0.12)$ & $-0.06(0.07)$ & $0.16(0.07)$ & 0.09 \\
\hline$\Delta 3-4$ months & $\mathrm{n}=14$ & $\mathrm{n}=59$ & $\mathrm{n}=64$ & \\
\hline WA & $0.04(0.06)$ & $-0.13(0.04)^{\mathrm{a}}$ & $0.09(0.03)^{\mathrm{b}}$ & $<0.001^{\star}$ \\
\hline LA & $0.04(0.08)$ & $-0.01(0.06)$ & $0.13(0.05)$ & 0.34 \\
\hline WL & $-0.03(0.10)$ & $-0.17(0.06)$ & $-0.05(0.05)$ & 0.47 \\
\hline$\Delta 4-6$ months & $\mathrm{n}=13$ & $\mathrm{n}=56$ & $\mathrm{n}=59$ & \\
\hline WA & $-0.22(0.07)^{\mathrm{a}}$ & $-0.13(0.05)^{\mathrm{a}}$ & $0.05(0.04)^{\mathrm{b}}$ & $0.006^{\star}$ \\
\hline LA & $-0.11(0.19)$ & $-0.13(0.06)^{\mathrm{a}}$ & $0.10(0.06)^{\mathrm{b}}$ & $0.009^{\star}$ \\
\hline WL & $-0.13(0.18)$ & $0.01(0.07)$ & $-0.03(0.07)$ & 0.73 \\
\hline$\Delta 6-9$ months & $\mathrm{n}=10$ & $\mathrm{n}=45$ & $\mathrm{n}=57$ & \\
\hline WA & $-0.01(0.14)$ & $0.03(0.07)$ & $0.12(0.06)$ & 0.15 \\
\hline LA & $0.07(0.19)$ & $0.09(0.12)$ & $0.16(0.06)$ & 0.70 \\
\hline WL & $-0.10(0.22)$ & $0.13(0.12)$ & $0.17(0.07)$ & 0.38 \\
\hline$\Delta 9-12$ months & $\mathrm{n}=11$ & $\mathrm{n}=43$ & $\mathrm{n}=56$ & \\
\hline WA & $-0.10(0.09)$ & $0.00(0.05)$ & $0.01(0.04)$ & 0.56 \\
\hline LA & $-0.02(0.30)$ & $0.00(0.07)$ & $0.06(0.05)$ & 0.46 \\
\hline WL & $-0.05(0.15)$ & $0.06(0.07)$ & $0.03(0.06)$ & 0.85 \\
\hline$\Delta 0-12$ months & $\mathrm{n}=13$ & $\mathrm{n}=48$ & $\mathrm{n}=56$ & \\
\hline WA & $-0.82(0.31)^{\mathrm{a}}$ & $-0.19(0.15)^{\mathrm{a}}$ & $0.37(0.13)^{\mathrm{b}}$ & $0.001^{\star}$ \\
\hline LA & $\begin{array}{l}-0.09(0.30) \\
\mathrm{n}=11\end{array}$ & $\begin{array}{l}0.08(0.12) \\
n=45\end{array}$ & $\begin{array}{l}0.26(0.30) \\
n=43\end{array}$ & 0.21 \\
\hline WL $\ddagger$ & $-0.30(0.28)^{\mathrm{a}}$ & $0.33(0.17)$ & $0.74(0.13)^{\mathrm{b}}$ & $0.009^{\star}$ \\
\hline
\end{tabular}

†Kruskal Wallis test; * significant.

a, b Different superscripts indicate between group significant differences (Dunn's post hoc analysis). $\ddagger$ Standardised data for WL at birth are unavailable for lengths $<49 \mathrm{~cm}$. showed steady LA $z$ score increments from the third month up to 12 months.

At the end of the survey the mean (SEM) WA $\mathrm{z}$ score of infants breast fed throughout the first 12 months of life was negative but close to $0(-0.04(0.26))$, while the score for the other breast fed infants was positive $(0.12(0.13))$. The 12 month breast fed infants also showed very similar mean values for LA $(-0.03(0.25))$ and WL $(0.10(0.30))$, while formula fed infants showed non-significantly higher values for WA, LA, and WL compared to both breast fed groups. The 0-12 month changes in the three growth parameters were negative in the 12 month breast fed group and positive in the formula fed group, the changes being significant for WA and WL.

\section{Discussion}

Our findings highlight different growth patterns, more pronounced during the first 6 months of life, in breast fed and formula fed infants. In the second six months of life breast fed infants show a progressive decline in growth rate (particularly in those breast fed for 12 months) while the formula fed group showed a progressive continuous rise. This is consistent with results from previous studies, ${ }^{1}$ where major growth differences (in terms of reduced WA and WL accretion of 12 month breast fed infants) had been recorded also in the second part of the year, as in the Davis area research on lactation, infant nutrition and growth (DARLING) study. ${ }^{11}{ }^{12}$ The inclusion of a large number of subjects breast fed for 12 months in the DARLING survey could have further emphasised the differences with the formula fed group. Indeed, in our study the 4-11 month breast fed group did not show any decrease in WA, LA, and WL in the 6-12 month period, while 12 month breast fed infants did.

Our 12 month breast fed babies had exceptionally higher WA and WL $\mathrm{z}$ scores at birth compared to those who were formula fed, as seen in male breast fed infants in the DARLING study who displayed a $+250 \mathrm{~g}$ WA difference at birth compared to their formula fed counterparts. ${ }^{11}$ This finding could reflect a more efficient placental nutrient supply to the fetus. By 1 month the values became similar to those of the other breast fed infants, who gained more weight in the first month. From the second month onwards the accelerated growth rate of the formula fed group allowed these infants to reach the WA, LA, and WL values of their breast fed counterparts in the 6-9 month period, and then to be heavier and taller (though non-significantly) at the end of the year.

While the observed patterns are in line with findings from other studies, ${ }^{12}$ a difference in the absolute standardised growth values is evident. Indeed, cumulative data on 12 month breast fed infants from different north European and North American countries show WA and WL $z$ scores at 12 months of -0.6 and -0.3 , respectively. ${ }^{12}$ Differences in genetic background could partly explain this. Clearly, while new growth curves of breast fed infants 
are under investigation, ${ }^{4}$ we need more data from developed south European and South American countries after adjusting for differences in ethnic and genetic backgrounds (including parental weight and height).

It is unlikely that peculiarities of weaning practices in Italy might be the cause of the less notable depression of WA and WL $\mathrm{z}$ scores in both breast fed groups at 12 months, when compared with other studies. ${ }^{12}$ We have already shown that the energy and macronutrient intake at the end of the weaning period in toddlers from our area is similar to that described in other well developed countries. ${ }^{13}$ It has been shown that the addition of solids has no effect on the energy intake of breast fed infants, since they respond with a reduction in breast milk intake, leading to the speculation that breast fed infants are able to self regulate their total energy intake. ${ }^{14} 15$ Thus, the growth decline of breast fed groups in the first year of life is unlikely to be caused by an inadequacy of food intake, at least in developed countries. We speculate, in agreement with others, ${ }^{2}$ that infants who are heavier initially may be less likely to be given supplements, thus reflecting a form of self selection for those who are breast fed for a longer period. Accordingly, a longer duration of breast feeding is associated with a greater decline in WA and WL using current reference data (as we have found in the $0-12$ month observations), but we expect functional outcome to be optimal. ${ }^{2}$

In conclusion, we confirm higher rates of growth increments for breast fed subjects in the early stages of extrauterine life and for formula fed subjects later. When using WHO reference curves, breast fed Italian infants show a less notable growth decline at the end of the first year of life in comparison with observations from north European and North American countries, possibly because of the genetic and ethnic diversity of our population. We specu- late that the higher standardised values for weight at birth in those who were breast fed longer may indicate an epidemiological link between more favourable intrauterine conditions and breast feeding success. We believe that this should be addressed in further investigations.

1 WHO Working Group on Infant Group, Nutrition Unit. An evaluation of infant growth: the use and interpretation of anthropometry in infants. Bull WHO 1995;73:165-74.

2 Dewey KG, Peerson JM, Brown KH, et al. Growth of breast-fed infants deviates from current reference data: a pooled analysis of US, Canadian, and European data sets. Pediatrics 1995;96:495-503.

3 Dibley MJ, Staehling N, Nieburg P, Trowbridge FL. Interpretation of Z-score anthropometric indicators derived from the international growth reference. Am f Clin Nutr 1987;46:749-62.

4 de Onis M, Garza C. Time for a new growth reference. Pediatrics 1997;100:(5) URL: http://www.pediatrics.org/cgi/ content/full/100/5/e8.

5 de Onis M, Habicht JP. Anthropometric reference data for international use: recommendations from a World Health Organization expert committee. Am f Clin Nutr 1996;64: $650-8$.

6 Hendricks KM, Badruddin SH. Weaning recommendations: the scientific basis. Nutr Rev 1992;50:125-33.

7 World Health Organization Global Data Bank on Breastfeeding. Breastfeeding: the best start. Geneva: WHO, 1996.

8 European Society of Pediatric Gastroenterology and Nutrition Committee on Nutrition. Guidelines on infant nutrition. I. Recommendation for the composition of an nutrition. I. Recommendation for the composition of an
adapted formula. Acta Paediatr Scand 1977;66(suppl 262): adapted $1-20$.

9 European Society of Pediatric Gastroenterology and Nutrition Committee on Nutrition. Recommendation for the composition of follow-up formula and Beikost. Acta Paediatr Scand 1981;70(suppl 287):1-25.

10 Hamill PVV, Drizd TA, Johnson CL, et al. Physical growth: National Center for Health Statistics percentiles. Am $\mathcal{F}$ Clin Nutr 1979;32:607-29.

11 Dewey KG, Heinig MJ, Nommsen LA, et al. Growth of breast-fed and formula-fed infants from 0 to 18 months: the DARLING study. Pediatrics 1992;89:1035-41.

12 Dewey KG, Heinig MJ, Nommsen LA. Breast-fed infants are leaner than formula-fed infants at 1 year of age: the DARLING study. Am f Clin Nutr 1993;57:140-5.

13 Bellù R, Ortisi MT, Incerti P, et al. Nutritional survey on a sample of one-year-old infants in Milan: intake of sample of one-year-old infants in Milan

14 Stuff JE, Nichols BL. Nutrient intake and growth performance of older infants fed human milk. F Pediatr 1989;115: 959-68.

15 Cohen RJ, Brown KH, Canahuati J, Rivera LL, Dewey KJ. Effects of age of introduction of complementary foods on infant breast milk intake, total energy intake, and growth: a randomised intervention study in Honduras. Lancet 1994;344:288-93. 